\title{
Sexually Dimorphic Responses of the Brain Norepinephrine System to Stress and Corticotropin-Releasing Factor
}

\author{
Andre L Curtis*,', Thelma Bethea' and Rita J Valentino' \\ 'The Children's Hospital of Philadelphia, Department of Pediatrics, Philadelphia, PA, USA
}

\begin{abstract}
Stress-related psychiatric disorders are more prevalent in females than males, and this has been attributed to differences in stress sensitivity. As activation of the locus coeruleus (LC)-norepinephrine (NE) system is an important component of the stress response, this study compared LC responses to stress in female and male rats under different hormonal conditions in the halothane-anesthetized state. The mean basal LC discharge rate was similar between groups. However, the magnitude of LC activation elicited by hypotensive stress was substantially greater in females, regardless of hormonal status. The difference in stress sensitivity could be attributed to the differential postsynaptic sensitivity of LC neurons to corticotropin-releasing factor (CRF), which mediates LC activation by hypotension. CRF was 10-30 times more potent in activating LC neurons in female vs male rats. Interestingly, previous exposure to swim stress differentially regulated $L C$ responses to CRF by sensitizing $L C$ neurons of male, but not female, rats to CRF. The net effect of this was to abolish sex differences in LC sensitivity. Finally, CRF receptor (CRF-R) protein levels in the LC were greater in ovarectomized female vs male rats. This is the first study to demonstrate sex differences in the stress responsiveness of the brain noradrenergic system. Substantial sex differences were apparent in postsynaptic sensitivity to CRF and stress-induced regulation of postsynaptic sensitivity to CRF. These sex differences in the CRF regulation of the LC-NE system translate to a differential response to stress and may play a role in the increased vulnerability of females to stress-related psychiatric disorders.

Neuropsychopharmacology (2006) 3 I, 544-554. doi:I 0. I038/sj.npp. I 300875; published online 24 August 2005
\end{abstract}

Keywords: locus coeruleus; norepinephrine; corticotropin-releasing factor; sex differences; gonadectomized; hypotension

\section{INTRODUCTION}

The incidence of stress-related psychiatric disorders, particularly depression, is significantly greater in females than in males (Earls, 1987; Whitaker et al, 1989; Breslau, 2001, 2002; Carter-Snell and Hegadoren, 2003; Kuehner, 2003). The role of stress in depression is particularly compelling, given that stressful life events can be identified in the majority of cases (Frank et al, 1994; Kendler et al, 1995). Many aspects of major depression resemble a stress response that is not counter-regulated, including hypothalamic-pituitary-adrenal (HPA) hyperactivity, HPA insensitivity to corticosteroid feedback, corticotropin-releasing factor (CRF) hypersecretion, and decreased sleep, appetite, and libido (Gold et al, 1988a, b; Chrousos and Gold, 1992; Nemeroff, 1996; Gold and Chrousos, 2002). The higher incidence of depression in females has led to speculation that hormonal influences on components of the HPA axis

* Correspondence: Dr AL Curtis, Department of Pediatrics, The Children's Hospital of Philadelphia, 409 G Abramson Pediatric Research Center, Philadelphia, PA 19104, USA, Tel: + I 215590 0654, Fax: + I 215590 3364, E-mail: curtisa@email.chop.edu

Received 9 May 2005; revised and accepted 7 July 2005

Online publication: 18 July 2005 at http://www.acnp.org/citations/ Npp07/805050309/default.pdf may contribute to dysfunctions. In support of this, rodent studies have demonstrated elevated basal and stressinduced corticosterone secretion in female rats (Kitay, 1961; Critchlow et al, 1963; Le Mevel et al, 1979; Seale et al, 2004). Moreover, estrogen has been demonstrated to impair glucocorticoid negative feedback (Burgess and Handa, 1992). In contrast, results of human studies are equivocal. There are demonstrations of an enhancement of the HPA response to stress or CRF in females (Gallucci et al, 1993; Jezova et al, 1996; Stroud et al, 2002) and estrogen-mediated increases in cortisol response in males (Kirschbaum et al, 1996). However, there are also reports of increased HPA responsivity in males (Kudielka et al, 1998; Kirschbaum et al, 1999; Traustadottir et al, 2003).

Although attention has focused on sex differences in the HPA response to stress, sex differences in other components of the stress response may contribute to the increased prevalence of depression in females. Activation of the locus coeruleus (LC)-norepinephrine (NE) system is a consistent response to stress that may function to optimize the state of arousal and mode of attention for adaptation to the challenge (Chrousos and Gold, 1992; O'Connor et al, 2000; Leonard, 2001; Vermetten and Bremner, 2002; Berridge and Waterhouse, 2003; Valentino and Van Bockstaele, 2005). As these functions are disrupted in depression and depression 
responds to agents that modulate brain NE activity, the LC$\mathrm{NE}$ system is another potential substrate for sex differences in stress-related disorders. Although there are reports of sex differences in the morphological characteristics of the LC (Luque et al, 1992; Babstock et al, 1997; Pinos et al, 2001), sex differences in neuronal activity have not been well investigated.

The present study investigated sex differences in the acute stress responsivity of the rat LC-NE system by comparing LC neuronal activation induced by hypotensive stress or CRF, which mediates LC activation by hypotensive stress (Valentino et al, 1991; Curtis et al, 1994). As prior exposure to stress has been demonstrated to produce long-term changes in CRF-LC interactions (Curtis et al, 1995, 1999), $\mathrm{LC}$ responses to hypotension and CRF were also compared $24 \mathrm{~h}$ after exposure to swim stress. In addition to the electrophysiological end points of LC activity, levels of CRF receptor protein in the LC were compared between male and female rats.

\section{METHODS}

\section{Animals}

The subjects were adult Sprague-Dawley rats (Charles River, Wilmington, MA) at least 9 weeks old at the beginning of experiments. Rats were either intact or were gonadectomized by the vendor at 6 weeks of age. Rats were housed three to a cage in a controlled environment $\left(20^{\circ} \mathrm{C}\right.$, $12 \mathrm{~h}$ light/dark cycle, lights on at $0700 \mathrm{~h}$ ) and allowed at least 3 weeks recovery from the procedure date stated in vendor surgical records. Experiments using intact rats were also carried out at least 2 weeks after arrival. Food and water were available ad libitum. Care and use of animals was approved by the Children's Hospital of Philadelphia IACUC, and was in accordance with the NIH Guide for the Care and Use of Laboratory Animals. To determine the potential role of sex hormones in LC responses to stress, female rats were ovariectomized without hormonal replacement (FO) or were administered estrogen $(20 \mu \mathrm{g}$, s.c.) $24 \mathrm{~h}$ prior to experiment (FE) or administered estrogen $(20 \mu$ g, s.c.) $24 \mathrm{~h}$ prior to experiment and progesterone $(1.0 \mathrm{mg}$, s.c.) $4 \mathrm{~h}$ prior to experiment (FEP). These doses and the treatment protocol were similar to those used in previous studies, and are based on the ability of hormone replacement to induce sexual receptivity in ovariectomized female rats (Frye et al, 1998; Perrotti et al, 2000; for a review, see Pfaff et al, 1994). To determine the effectiveness of hormone replacement in female rats, the uterus was dissected and removed at the end of the experiment and the diameter was measured using calipers. Uterine diameters for FE $(3.6 \pm 0.1 \mathrm{~mm}, n=13)$ and FEP $(3.7 \pm 0.1$, $n=13)$ rats were significantly greater compared to those of FO rats $(2.6 \pm 0.1, n=40)(\mathrm{F}(2,65)=83, p<0.001$, one-way ANOVA). Likewise, in a second study in rats with prior swim stress, the mean uterine diameter in FE $(3.9 \pm 0.1 \mathrm{~mm}$, $n=34)$ and FEP $(3.8 \pm 0.1 \mathrm{~mm}, n=10)$ rats was greater than that in FO rats $(2.6 \pm 0.1 \mathrm{~mm}, n=41)(\mathrm{F}(2,84)=111$, $p<0.001)$. The male rats used were either intact (MI) or gonadectomized (MG). In each shipment, males and females were littermates.

\section{Surgery}

The surgical and recording procedures were similar to those described previously (Curtis et al, 1997). Rats were anesthetized with $2 \%$ halothane-in-air mixture administered through a nose cone. The jugular vein and femoral artery were cannulated for intravenous (i.v.) infusion of nitroprusside and continuous direct monitoring of blood pressure, respectively. The anesthetic was maintained at $1.0-1.5 \%$ throughout the experiment. Body temperature was maintained at $37.5^{\circ} \mathrm{C}$ by a feedback-controlled heating pad. Rats were positioned in a stereotaxic instrument using blunt ear bars, with the head oriented at $15^{\circ}$ angle to the horizontal plane (nose down). The skull was exposed, and a hole (approximately $3 \mathrm{~mm}$ diameter), centered at $1.2 \mathrm{~mm}$ lateral to the midline and $3.5-3.7 \mathrm{~mm}$ caudal to lambda, was drilled over the cerebellum for approaching the LC. The dura over the cerebellum was carefully removed with fine iridectomy scissors to facilitate introduction of the recording micropipette.

\section{Recording}

Single barrel glass micropipettes $(2-4 \mu \mathrm{m}$ diameter tip, 4-7 MOhm) filled with $0.5 \mathrm{M}$ sodium acetate buffer saturated with Pontamine Sky Blue dye (PSB) were used to record single-unit LC discharge. In experiments involving intra-LC administration of $\mathrm{CRF}$, double-barrel glass micropipettes were used to record single-unit LC discharge and simultaneously microinfuse CRF (Akaoka et al, 1992; Curtis et al, 1997). The microinfusion pipette (Fisher Scientific, Pittsburg, PA; $60-90 \mu \mathrm{m}$ diameter tip) was angled at $30-45^{\circ}$ with its tip adjacent and $130-150 \mu \mathrm{m}$ dorsal to the tip of the recording pipette and glued in this alignment using a photopolymerizing two-part resin (Silux, $3 \mathrm{M}$ Dental Products, St Paul, MN). The micron-fusion pipette was connected by tubing to a source of solenoid-activated pneumatic pressure (Picospritzer, General Valve, Fairfield, NJ) and calibrated such that known volumes could be administered. Intracoerulear infusions were made by applying small pulses of pressure $(15-25 \mathrm{psi}, 10-30 \mathrm{~ms}$ in duration) to the peptide-containing barrel at a frequency of $0.2-1.0 \mathrm{~Hz}$. The movement of the meniscus of the solution through the calibrated pipette was observed through a dissecting scope with respect to a fixed piece of metric chart paper. Displacement of the meniscus by $0.5 \mathrm{~mm}$ corresponded to a $30 \mathrm{nl}$ injection. Microinfusions of peptide solution to the microenvironment of the recorded LC unit occurred over 1-3 min.

The micropipette was advanced toward the LC with a micromanipulator. Neuronal signals were amplified and filtered. Impulse activity was monitored with an oscilloscope and a loudspeaker to aid in localizing the LC. LC neurons were tentatively identified during recording by their spontaneous discharge rates $(0.5-5 \mathrm{~Hz})$, entirely positive, notched waveforms ( $2-3 \mathrm{~ms}$ duration), and biphasic excitation-inhibition responses to contralateral hindpaw or tail pinch. When stable, unitary action potentials were isolated, a window discriminator was used to convert the occurrence of a single action potential into a digital pulse, which was led into a Windows-based computer via a CED 1401 interface (Cambridge Electronic Design, Cambridge, 
UK) using Spike 2 software for on-line visualization and storage and off-line analysis.

\section{Protocol}

Extracellular single-unit LC spontaneous discharge was recorded until stable (4-6 min), and hypotensive stress was elicited by sodium nitroprusside infusion $(0.33 \mathrm{mg} / \mathrm{ml}$, $30 \mu \mathrm{l} / \mathrm{min}, 15 \mathrm{~min}$ duration, i.v.). LC discharge rate and mean arterial blood pressure (MAP) were continuously recorded during and after the infusion (an additional $15 \mathrm{~min}$ ). MAP was monitored with a pressure transducer and amplifier and the signal was led to a Windows-based computer via the CED 1401 interface using Spike2 software. Nitroprusside was infused only once to an individual rat.

In experiments assessing the effects of CRF, LC discharge was recorded for 3-6 min before and for up to $15 \mathrm{~min}$ after CRF microinfusion. Only one cell from an individual rat was tested and only one dose of CRF was tested on an individual cell.

In a second study that examined the impact of prior swim stress on LC activity, rats were placed in a cylindrical glass tank $(46 \mathrm{~cm}$ height $\times 20 \mathrm{~cm}$ diameter) filled with water $\left(25 \pm 1^{\circ} \mathrm{C}\right)$ to a depth of $30 \mathrm{~cm}$ for $15 \mathrm{~min}$. The $30-\mathrm{cm}$ depth allowed rats to swim or float without having their tails touch the bottom of the tank. Immediately after the 15-min swim, rats were removed from the tank, towel dried, and put in a warming cage $\left(37^{\circ} \mathrm{C}\right)$ that contained a heating pad covered with towels for $15 \mathrm{~min}$. Rats were then returned to their home cage. On the following day (24 h after exposure to water), rats were anesthetized with halothane and surgically prepared for LC neuronal recording as described above. For rats receiving hormone replacement, estrogen was administered within $5 \mathrm{~min}$ after the end of forced swim, so that hormone replacement was not a factor during forced swim.

\section{Histology}

The recording site was marked by iontophoresis $(-15 \mu \mathrm{A}$, $10 \mathrm{~min}$ ) of PSB at the end of the experiment. Rats were anesthetized with pentobarbital $(100 \mathrm{mg} / \mathrm{kg}$, i.p.) and perfused with a $4 \%$ solution of paraformaldehyde in phosphate buffer (PB). Brains were removed and frozen $40-\mu \mathrm{m}$-thick coronal sections were cut on a cryostat, mounted on gelatinized glass slides, and stained with neutral red for localization of the PSB spot. The data presented are from neurons that were histologically identified as being within the nucleus LC (Valentino et al, 1983).

\section{Electrophysiological Data Analysis}

Unless otherwise stated, the selection of the treatment group that provided a subject for a given experiment was determined by a process of randomization using a random number table. Mean baseline discharge rate and MAP of the treatment groups were compared by a one-way factorial ANOVA. For quantification of $\mathrm{LC}$ responses to hypotensive challenge, the mean preinfusion discharge rate $(4-6 \mathrm{~min})$ was determined and LC discharge rates during and after nitroprusside infusion were expressed as a percentage of this baseline value. Effects were analyzed by two-way ANOVA, with group as a between-subjects factor and time as the within-subjects factor. Additionally, the mean maximum discharge rate in any 3-min interval during nitroprusside infusion was compared to the respective mean baseline rate by paired Student's $t$-test (two-tailed) to assess the statistical significance of the peak activation within an individual treatment group. The peak inhibition of the postinfusion interval was defined as the lowest discharge rate in any 3-min interval during $15 \mathrm{~min}$ after the end of nitroprusside infusion, and was expressed as a percentage decrease from the baseline rate. Comparisons of peak LC activation (percent increase) or peak LC inhibition (percent decrease) across the treatment groups used a one-way factorial ANOVA. Scheffe's F-test was used post hoc to determine statistically significant differences at individual time points or between group pairs in factorial analyses. Other comparisons used unpaired Student's $t$-test or twoway factorial ANOVA where appropriate.

For LC responses to CRF, the mean maximum percentage increase in LC discharge rate in any 3-min interval within $15 \mathrm{~min}$ after completion of infusion of a given dose of CRF was used to generate the dose-response curve. Statistical significance within a group was determined by the paired Student's $t$-test. Statistical differences between CRF dose-response curves were determined by a two-way factorial ANOVA. The unpaired Student's $t$-test was used to compare the effects of a single dose of CRF between groups.

\section{Western Blot Analysis}

Rats (MI or FO) were euthanized by decapitation and brains placed in a block from which a slice $(2 \mathrm{~mm})$ containing the LC was cut. The cerebellum was removed and tissue containing the LC was microdissected using a trephine. Samples were homogenized and centrifuged. Protein content was determined using the BCA method. Protein extracts $(15 \mu \mathrm{g})$ were subjected to SDS-PAGE gel electrophoresis, and proteins were transferred to a polyvinylidene difluoride membrane. Membranes were incubated in goat anti-CRF-R antiserum (1:500, Santa Cruz Biochemical, Santa Cruz, CA) for $1 \mathrm{~h}$ at room temperature. This antibody is directed against the C-terminus of the CRF-R1 receptor, but crossreacts with CRF-R2. Membranes were rinsed and incubated with peroxidase-conjugated donkey anti-goat antiserum (1:10000; Jackson ImmunoResearch, West Grove, PA). Nonspecific binding was blocked by incubation in $2 \%$ bovine serum albumin (BSA). The membranes were developed using an ECL kit (Amersham Biosciences, Piscataway, NJ) and exposed to an X-OMAT AR film (Eastman Kodak, Rochester, NY). After probing for CRF-R, the membranes were stripped using Re-Blot Plus (Chemicon, Temecula, CA), blocked in the BSA solution and incubated in mouse anti- $\beta$-actin antibody ( $1: 5000$; Sigma, St Louis, MO). Membranes were processed as above using a donkey anti-mouse antibody. Films were scanned and band density was quantified using UN-SCAN-IT (Silk Scientific, Orem, UT). CRF-R: actin ratios were calculated for each sample and compared using unpaired Student's $t$-test. Duplicate or triplicate samples from the same rat were averaged for an individual determination. 


\section{Immunohistochemistry}

Rats (MI or FO) were anesthetized with sodium pentobarbital (50 mg/kg, i.p.) and transcardially perfused with $50 \mathrm{ml}$ heparinized saline followed by $500 \mathrm{ml}$ of $4 \%$ paraformaldehyde in $0.1 \mathrm{M} \mathrm{PB}$. Brains were removed, postfixed for at least $1 \mathrm{~h}$ and transferred to a $20 \%$ sucrose solution in $\mathrm{PB}$ containing $0.1 \%$ sodium azide for at least $24 \mathrm{~h}$. Coronal $10-\mu \mathrm{m}$-thick sections were cut through the LC and mounted onto slides (Fisher Probe-on Plus, Fisher, Morris Plains, NJ). These were rinsed in phosphate-buffered saline (PBS; $\mathrm{pH}$ 7.4) and incubated in a solution containing the goat anti-CRF-R antibody $(1: 1000)$ and mouse anti-tyrosine hydroxylase $(\mathrm{TH})$ antisera $(1: 2000$, ImmunoStar, Hudson, WI) in PBS containing $0.3 \%$ Triton-X 100, $0.04 \%$ BSA (PBST-BSA) and $0.1 \%$ sodium azide for $48 \mathrm{~h}$ at $4{ }^{\circ} \mathrm{C}$. Slides containing sections from $\mathrm{MI}$ and $\mathrm{FO}$ rats were processed together using the same solutions. The slides were rinsed and incubated in a solution containing rhodamine-conjugated donkey anti-goat antibody ( $1: 200$, Jackson Laboratories, West Grove, PA) and fluorescein-conjugated donkey anti-mouse antibody (1:200, Jackson Laboratories) for $90 \mathrm{~min}$ at room temperature. Sections were rinsed and coverslipped. CRF-R and TH were visualized with rhodamine and fluorescein filters, respectively. Images were captured with a Hamamatsu ORCA-ER digital camera (Bridgewater, NJ) using Open Lab software (Improvision, Coventry, UK). For densitometric quantification, sections containing the central part of the LC were selected from images of TH staining. An outline of the nucleus based on $\mathrm{TH}$ staining was drawn and superimposed on the corresponding rhodamine image of the same section. The image was cut around this outline so that only this portion of the section was subjected to densitometry. The rhodamine image was converted to grayscale and inverted so that staining appeared as black on white background for densitometry measurements. The image was imported into NIH Image for densitometry measurements. Measurements were obtained from at least 10 sections from three rats for each group.

\section{Drugs}

Estrogen (beta-estradiol 3-benzoate) and progesterone (Sigma Chemical Co., St Louis, MO) were dissolved in sesame oil. Ovine CRF was generously supplied by Dr Jean Rivier of the Clayton Foundation Laboratory for Peptide Biology (The Salk Institute, San Diego, CA). The peptide was dissolved in water to make a $1.0 \mathrm{mg} / \mathrm{ml}$ solution. Aliquots $(10 \mu \mathrm{l})$ of the solution were concentrated using a Savant Speed Vac concentrator. The $10 \mu \mathrm{g}$ aliquots were stored at $-70^{\circ} \mathrm{C}$ and dissolved in artificial cerebrospinal fluid (ACSF) on the day of the experiment. Sodium nitroprusside (Sigma Chemical Co.) was dissolved in saline on the day of the experiment.

\section{RESULTS}

\section{LC Spontaneous Discharge Rate}

The mean baseline discharge rate of all LC neurons for each group was $1.9 \pm 0.1 \mathrm{~Hz}$ for $\mathrm{MI}(n=88), 2.2 \pm 0.2 \mathrm{~Hz}$ for $\mathrm{MG}$ $(n=10), 1.7 \pm 0.1 \mathrm{~Hz}$ for $\mathrm{FO}(n=58), 1.6 \pm 0.1 \mathrm{~Hz}$ for $\mathrm{FE}$ $(n=13), 1.8 \pm 0.1 \mathrm{~Hz}$ for FEP $(n=13)$, and $1.9 \pm 0.1 \mathrm{~Hz}$ for FI $(n=16)$. These rates were not significantly different; $\mathrm{F}(5,197)=1.4, p>0.1$.

\section{Sex Differences in LC Responses to Hypotensive Stress}

Figure 1 shows the time-course of mean LC activity during and after hypotensive challenge. LC activity was significantly increased during nitroprusside infusion in all groups of rats $(p<0.05$, paired Student's $t$-test $)$, although the magnitude of LC activation in these MI rats obtained from Charles River was less than that previously reported in MI rats from Taconic Farms (Valentino et al, 1991; Curtis et al, $1994,1995,2001,2002)$. This stress produced a substantially greater activation of LC neurons of all female groups, irrespective of hormonal status, compared to either MI or MG rats (Group effect; $\mathrm{F}(5,68)=5.2, p<0.001$, two way ANOVA with repeated measures $0-12 \mathrm{~min}$ ). In contrast, the magnitude of poststress inhibition was comparable between the male groups and FO, FE and FEP groups $(\mathrm{F}(4,40)=0.4$, $p>0.1$, two-way ANOVA with repeated measures 18$24 \mathrm{~min}$ ). (Note that the FI group was not included in this statistical analysis because an insufficient number of neurons maintained recording stability for a time greater than 6 min poststress.) In concert with time-course findings,

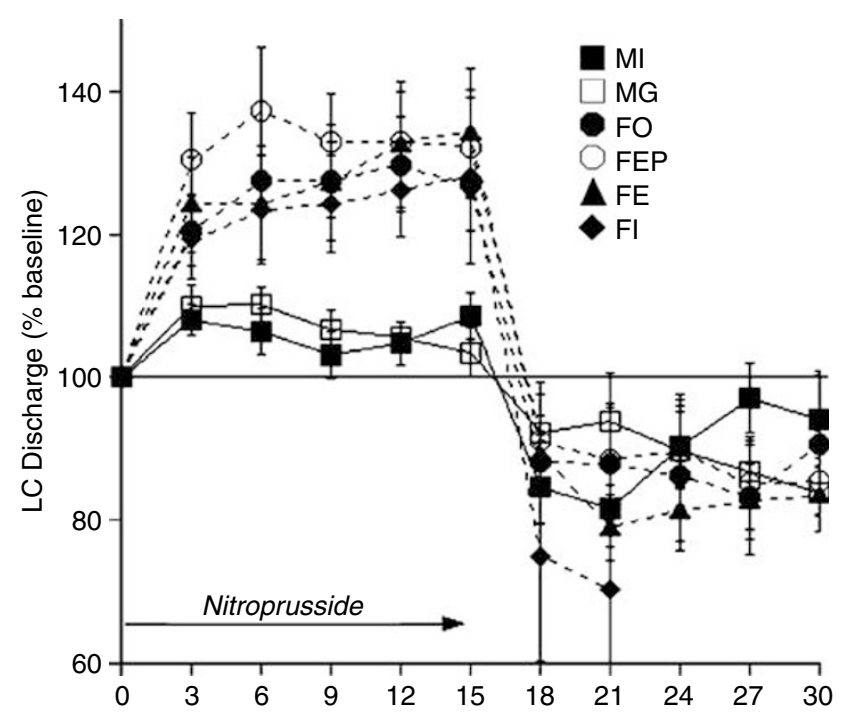

Figure I LC activation during hypotensive challenge is greater in female vs male rats. The ordinate indicates LC discharge rate expressed as a percentage of mean baseline rate. The abscissa indicates time ( $\mathrm{min}$ ) and the arrow beneath 'Nitroprusside' indicates the time of i.v. infusion ( 0 - 15 min). Shown are curves representing the time-course of the mean LC response during and after nitroprusside infusion for $\mathrm{MI}(n=16-23$ cells), MG $(n=8-$ 10 cells), FO ( $n=9-13$ cells), FE ( $n=11-13$ cells), FEP ( $n=7-13$ cells), and $\mathrm{FI}(n=5-10$ cells) rats. Vertical lines represent \pm I SEM. Comparisons of the time-course of LC responses over $0-12$ min showed a significantly attenuated response in $\mathrm{MI}(2 \mathrm{I}$ cells) compared to $\mathrm{FO}$ ( 13 cells, Group effect; $F(I, 32)=16.9, p<0.001$ ), FE (I 2 cells, Group effect; $F(|, 3|)=12.2$, $p<0.005)$, FEP (I0 cells, Group effect; $F(1,29)=18.1, p<0.001$ ), and FI (nine cells, Group effect, $F(I, 28)=9.8, p<0.005$ ) using two-way ANOVA with repeated measures. Likewise, the response was attenuated in MG rats compared to FO (Group effect; $F(I, 20)=8.8, p<0.01$ ), FE (Group effect, $F(I, 19)=5.4, p<0.05$ ), FEP (Group effect, $F(I, I 7)=8.8, p<0.0 I$ ), and $F I$ (Group effect, $F(I, 16)=5.1, p<0.05$ ). 
Table I Maximum Magnitude of Hypotension and LC Activation in Males vs Females

\begin{tabular}{|c|c|c|c|c|}
\hline & Hypotension $^{\mathrm{a}}$ (\% decrease) & LC $^{\mathrm{b}}$ (\% increase) & Basal MAP $(\mathrm{mmHg})$ & Basal LC ${ }^{\mathrm{d}}(\mathbf{H z})$ \\
\hline $\mathrm{Ml}(n=15)^{\mathrm{e}}(0.33 \mathrm{mg} / \mathrm{ml})$ & $5| \pm|$ 米 & $14 \pm 3 *$ & $77 \pm 1$ & $1.9 \pm 0.1$ \\
\hline $\mathrm{Ml}(n=7)(0.5 \mathrm{mg} / \mathrm{ml})$ & $55 \pm 1$ & $12 \pm 4 *$ & $78 \pm 2$ & $2.0 \pm 0.3$ \\
\hline$M G(n=10)(0.33 \mathrm{mg} / \mathrm{ml})$ & $60 \pm 1$ & $14 \pm 3 *$ & $79 \pm 2$ & $2.2 \pm 0.2$ \\
\hline $\mathrm{FO}(n=13)(0.33 \mathrm{mg} / \mathrm{ml})$ & $57 \pm 1$ & $37 \pm 6$ & $78 \pm 1$ & $1.7 \pm 0.2$ \\
\hline $\mathrm{FE}(n=13)(0.33 \mathrm{mg} / \mathrm{ml})$ & $56 \pm 1$ & $40 \pm 8$ & $80 \pm 2$ & $1.6 \pm 0.1$ \\
\hline
\end{tabular}

${ }^{a}$ There were differences in the hypotensive response between groups, $\mathrm{F}(6,80)=12.3, p<0.00 \mathrm{I} .{ }^{*} * \mathrm{MI}$ compared to all groups, ${ }^{\dagger} \mathrm{FI}$ compared to FE, FO, and $\mathrm{MI}$; Scheffe F-test.

${ }^{b}$ There were differences in the LC response between groups, $F(6,80)=4.3, p<0.01$. *Male groups and FO, FE, and FEP. Student's t-test unpaired revealed differences between male groups and $\mathrm{FI}(p<0.05)$

${ }^{\mathrm{c}}$ There were no significant differences among basal MAP $(\mathrm{mmHg})$ values, $\mathrm{F}(6,80)=0.5, p>0.1$.

'There were no significant differences among basal LC spontaneous discharge rates $(\mathrm{Hz}), \mathrm{F}(6,80)=0.9, p>0.1$.

eThis group of rats was separate from the group used in Figure I, and paired with Ml, receiving a higher concentration of nitroprusside ( $0.5 \mathrm{mg} / \mathrm{ml})$.

the mean maximum LC activation elicited by hypotensive stress was significantly greater in the female groups compared to males $(\mathrm{F}(5,96)=6.5, p<0.005)$ (see Figure 5). However, the mean maximum poststress inhibition (not shown) was not significantly different among the groups $(\mathrm{F}(5,65)=0.9, p>0.1)$.

Baseline MAP for all groups ranged between 60 and $92 \mathrm{mmHg}$, and was not significantly different between groups $(F(5,96)=1.1, p>0.1)$ (Table 1$)$. There were some small, but statistically significant, differences in the magnitude of hypotension elicited by nitroprusside between the groups. For example, although the magnitude of hypotension elicited in the MI group (Table 1) was comparable to that reported in previous studies using MI rats (Curtis et al, 1994, 2001), this was slightly less than the peak hypotension produced in all female groups $(\mathrm{F}(4,71)=11.7, p<0.005)$ or in $\mathrm{MG}$ rats in the present study $(p<0.005$, unpaired Student's $t$-test) (Table 1$)$. Within the female groups the hypotensive response to nitroprusside was comparable for FO, FE, and FEP $(\mathrm{F}(2,38)=0.2, p>0.1)$. However the hypotensive response was slightly higher in FI $(\mathrm{F}(3,48)=7.5, p<0.005)$ (Table 1$)$. These small differences in the hypotensive response between female groups were not reflected in differences in LC activation because this was similar across all female groups $(\mathrm{F}(3,48)=0.4, p>0.1)$ (Table 1$)$. Additionally, $\mathrm{MG}$ rats had a hypotensive response that was comparable to FI rats ( $p>0.1$, Student's $t$-test, unpaired), but, like MI rats, a significantly reduced LC activation (Table 1). Nonetheless, in a separate experiment, the concentration of nitroprusside administered to MI rats was increased from 0.33 to $0.5 \mathrm{mg} /$ $\mathrm{ml}$ in an effort to produce a hypotensive response that was equivalent to that produced in females. Table 1 shows that the higher dose of nitroprusside administered to MI rats produced a larger magnitude of hypotension compared to the lower dose $(p<0.05$, Student's $t$-test, unpaired) that was equivalent to the FO, FE, and FEP groups $(F(3,45)=0.7$, $p>0.1$ ). Importantly, normalizing the hypotensive response did not impact on sex differences in the magnitude of neuronal activation; that is, for a similar magnitude of hypotension, the magnitude of LC activation recorded in female rats was greater than that recorded in MI rats (Table 1).

\section{Sex Differences in LC Responses to Exogenous CRF}

As endogenous CRF mediates LC activation by hypotensive stress (Valentino et al, 1991; Curtis et al, 2001), the effects of CRF microinfusion into the LC on discharge rate were compared. Complete CRF dose-response curves were compared between MI and FO rats because there were no differences in LC responses to hypotensive challenge between FO, FE, and FEP. LC cells of FO rats were more sensitive to exogenous CRF, as suggested by a $10-30$-fold shift to the left in the CRF dose-response curve generated in FO rats compared to MI rats (Figure 2). Both the 3 and $30 \mathrm{ng}$ doses produced a greater magnitude of LC activation in FO vs MI rats (Group effect, $\mathrm{F}(1,30)=8.2, p<0.01$ for 3 and $30 \mathrm{ng}$, two-way ANOVA). Indeed, in MI rats $3 \mathrm{ng}$ CRF did not produce a significant increase of LC discharge above the mean baseline ( $p=0.4$, paired Student's $t$-test). Additionally, LC neurons of FO rats were activated by $1 \mathrm{ng}$ CRF $(p<0.05$, paired Student's $t$-test), a dose that would have failed to significantly activate LC neurons of MI rats (Figure 2). A dose of CRF (3 ng) that well discriminated LC responses between MI and FO rats also activated LC neurons of FI rats, and the magnitude of this activation was greater than that seen in MI rats $(p<0.01$, unpaired Student's $t$-test) (Figure 2, filled diamond). Interestingly, the magnitude of LC activation associated with hypotensive stress in females (approximately 30\% increase) would be equivalent to that produced by a dose of CRF between 1 and $3 \mathrm{ng}$. Based on the CRF dose-response curve generated in MI rats, this same dose range would be associated with a less than $10 \%$ increase in discharge rate (Figure 2), and this corresponds well with the experimental observation of the response to hypotension in the MI group (Figure 1).

\section{LC CRF-R Immunoreactivity}

To determine whether sex differences in LC sensitivity to CRF were due to differences in CRF receptor protein levels, 


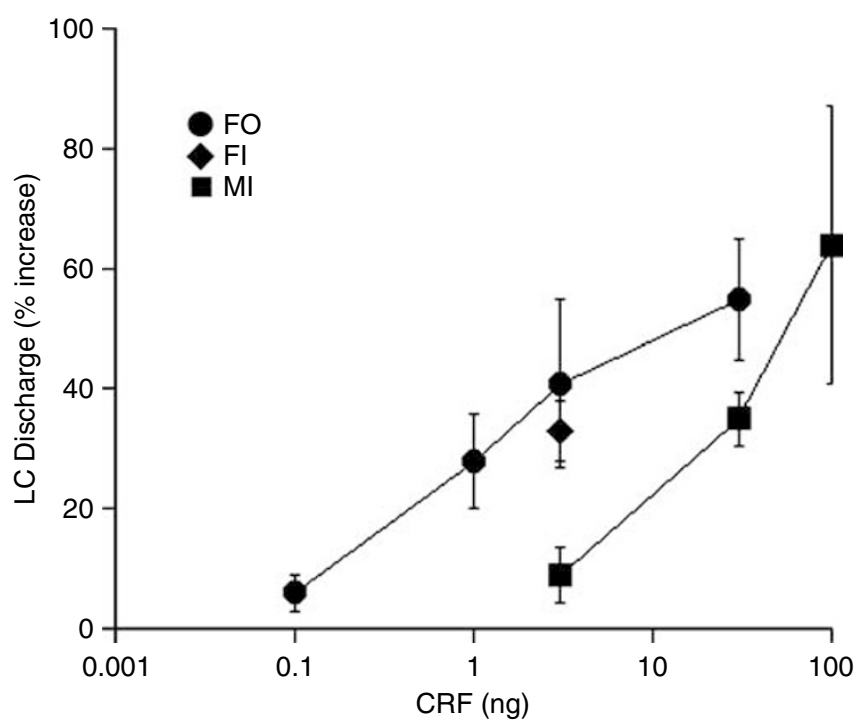

Figure 2 LC neurons of female rats are sensitized to CRF. CRF doseresponse curves for LC activation generated in FO vs MI. The abscissa indicates the dose of CRF (ng, log scale). The ordinate indicates the maximum percent increase produced by a dose of CRF expressed as percentage increase over the mean rate determined 4-6 min prior to CRF microinfusion. Each point is a mean of 5-10 cells. Vertical lines represent \pm SEM. For CRF doses 3 and $30 \mathrm{ng}$, LC activation in FO was significantly greater compared to $\mathrm{MI}$ (Group effect, $F(I, 30)=8.2, p<0.01$, two-way ANOVA). LC activation by $3 \mathrm{ng}$ CRF was greater in $\mathrm{Fl}$ compared to $\mathrm{Ml}$ $(p<0.0$ I, unpaired Student's t-test).

these were quantified in punches of LC tissue by Western blot analysis. Figure 3 shows representative Western blots of $\mathrm{CRF}$ receptor and actin immunoreactivity. The mean CRF-R: actin ratio was greater in FO vs MI rats $(p<0.05$, unpaired Student's $t$-test). Consistent with this, densitometric analysis of CRF receptor immunofluorescence revealed higher levels of CRF receptor in sections of FO vs MI rats (Figure 4).

\section{Sex Differences in LC Neurons in Rats with Stress Experience}

The mean baseline discharge rates of LC neurons in MI $(1.9 \pm 0.1, n=49)$, MG $(1.8 \pm 0.2, n=15)$, FO $(1.9 \pm 0.1$, $n=41)$, FE $(1.7 \pm 0.1, n=34)$, and FEP $(1.7 \pm 0.1, n=10)$ $24 \mathrm{~h}$ after swim stress were not significantly different across groups $[\mathrm{F}(4,148)=0.4, p>0.1]$. In line with previous reports (Curtis et al, 1999), the basal rates for the different groups after swim stress were comparable to the unstressed groups (Group effect: $\mathrm{F}(1,4)=0.01, p>0.1$ ). Thus, prior exposure to swim stress does not alter LC spontaneous discharge rate recorded $24 \mathrm{~h}$ later.

Prior exposure to swim stress increased LC activation by hypotensive challenge in both MI and MG rats, such that the responses were comparable to those of the FO and FEP groups $(F(3,50)=1.2, p>0.1)$ (Figure 5). Thus, swim stress appeared to abolish sex differences in LC responses to hypotensive stress. Although swim stress did not alter the magnitude of LC activation by hypotensive stress in FO or FEP rats, it had a uniquely inhibitory effect in FE rats, which exhibited a diminished response to hypotensive challenge compared to all other groups exposed to swim stress

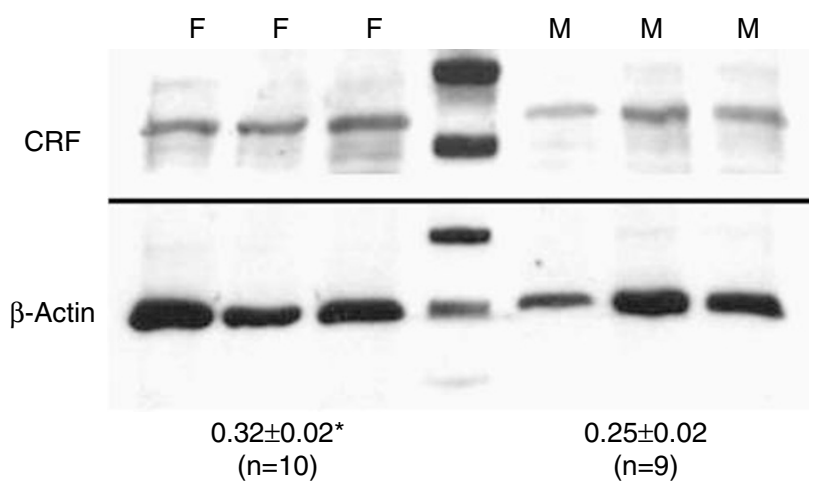

Figure 3 LC tissue from FO has higher levels of CRF-R compared to tissue from $\mathrm{Ml}$, as indicated by Western blots. Representative Western blots of CRF-R and actin in the same subjects. Blots were first probed for CRF-R, stripped, and re-probed for actin. The numbers below the blots are the mean CRF-R: $\beta$-actin ratios determined from IO FO and nine $\mathrm{MI}$, and numbers in parentheses indicate number of subjects per group; $* p<0.05$.

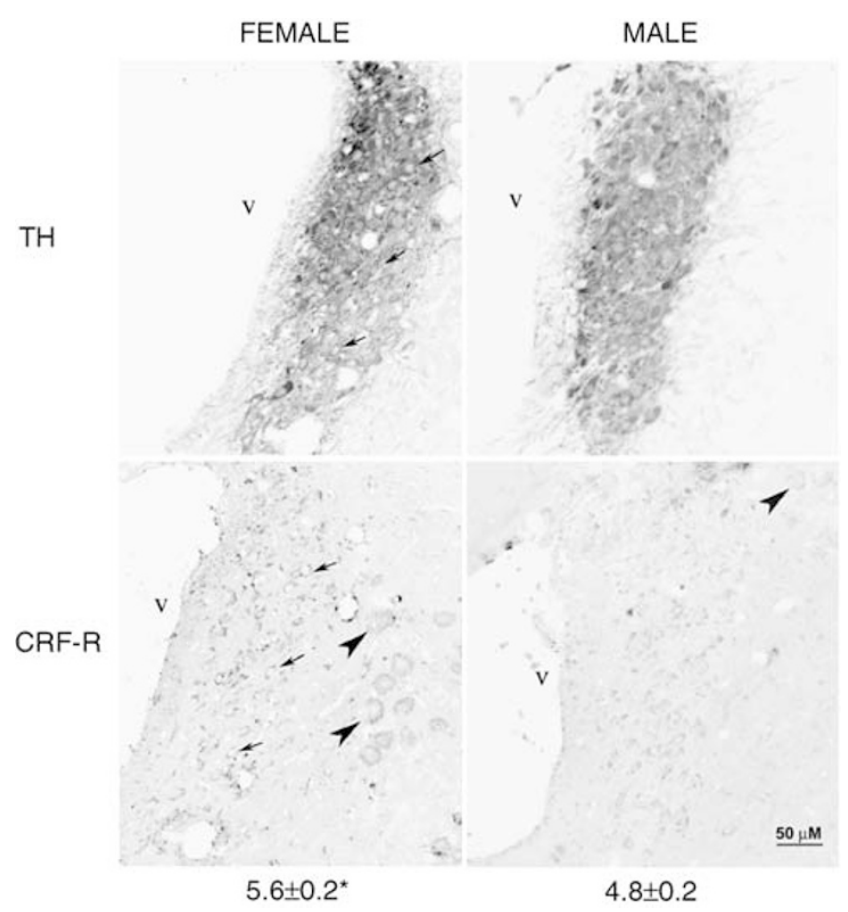

Figure 4 CRF-R immunoreactivity is denser in the LC in female vs male rats. The top panels show TH immunoreactivity in sections from a female and male rat. The image is inverted from a fluorescent image. The bottom panels show the same section visualized to detect CRF-R immunoreactivity as described in Methods. The arrowheads point to cells of the mesencephalic trigeminal nucleus. The arrows point to same neurons in both top (TH) and bottom (CRF-R) panels to show representative $\mathrm{TH}$ labeled cells that also stain for CRF-R. $v=$ fourth ventricle. The numbers below the images are the mean density determined from 10 sections from each of three rats for each group. ${ }^{*} p<0.05$, unpaired Student's t-test.

$(\mathrm{F}(4,60)=2.7, p<0.05)$ (Figure 5). Interestingly, the maximum poststress LC inhibition (not shown) was similar between FO, FE, and FEP rats $(\mathrm{F}(2,19)=0.8, p>0.1)$.

The poststress inhibition was overall similar between groups $(\mathrm{F}(4,39)=23.3, \quad p>0.1)$. However, a selective comparison revealed a somewhat greater magnitude of 


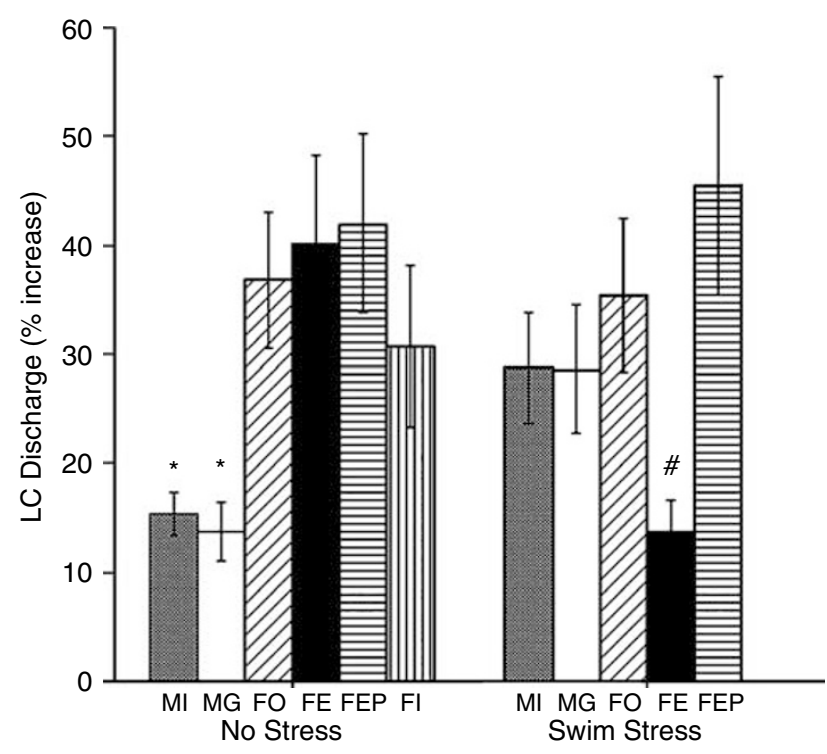

Figure 5 Sex differences in LC responses to stress are not apparent in rats with a history of prior swim stress. Bar graph representing the mean maximum LC activation during nitroprusside infusion in rats without a history of swim stress, or rats that were exposed to swim stress $24 \mathrm{~h}$ prior to $L C$ recording. The ordinate indicates percent increase in $L C$ discharge rate in MI ( $n=38$ cells for no stress and I 5 cells for swim), MG ( $n=10$ cells for no stress and I 5 cells for swim), $\mathrm{FO}$ ( $n=13$ cells for no stress and II cells for swim), FE ( $n=13$ cells for no stress and 10 cells for swim), FEP ( $n=13$ cells for no stress and 10 cells for swim), and FI ( $n=10$ cells). Vertical lines represent \pm I SEM. In rats with no history of swim stress, the maximum LC activation was significantly less in both male groups compared to each female group ( ${ }^{*} p<0.01$, unpaired Student's $t$-test). ${ }^{\#}<0.05$, unpaired Student's t-test compared to FO, FEP, and MI.

poststress inhibition in MI compared to MG rats $(p<0.05$, unpaired Student's $t$-test).

Consistent with its impact on LC responses to hypotensive challenge, prior swim stress negated sex differences in LC responses to CRF. Figure 6a shows CRF dose-response curves generated in $\mathrm{MI}$ and $\mathrm{FO}$ rats $24 \mathrm{~h}$ after swim stress. There were no differences in the response to CRF $(0.3-30 \mathrm{ng})$ between FO and MI groups (Group effect: $\mathrm{F}(1,56)=0.04, p=0.8)$. As swim stress decreased the magnitude of LC activation by hypotensive challenge uniquely in the FE group, a CRF dose-response curve was also generated in this group (Figure 6a). There were no differences in the response to CRF (1-30 ng) among $\mathrm{MI}$ and $\mathrm{FO}$ or FE rats (Group effect: $\mathrm{F}(2,68)=0.3$, $p=0.8)$.

Figure $6 \mathrm{~b}$ compares CRF dose-response curves in MI and FO rats that had stress experience to those that did not. Note that low doses of CRF ( 1 and $3 \mathrm{ng}$ ) that would not be effective in previously unstressed MI rats $(p>0.1$, paired Student's $t$-test for $3 \mathrm{ng}$ ) produced a statistically significant activation in MI rats $24 \mathrm{~h}$ after swim stress $(p<0.02$, paired Student's $t$-test). In contrast, the $30 \mathrm{ng}$ dose had similar effects in both groups ( $p>0.1$, unpaired Student's $t$-test). This stress-induced sensitization of LC neurons to low doses of CRF confirms previous studies in male rats (obtained from Taconic Farms) with a history of swim stress or shock experience (Curtis et al, 1995, 1999). The sensitization is apparent as a shift to the left in the low-dose
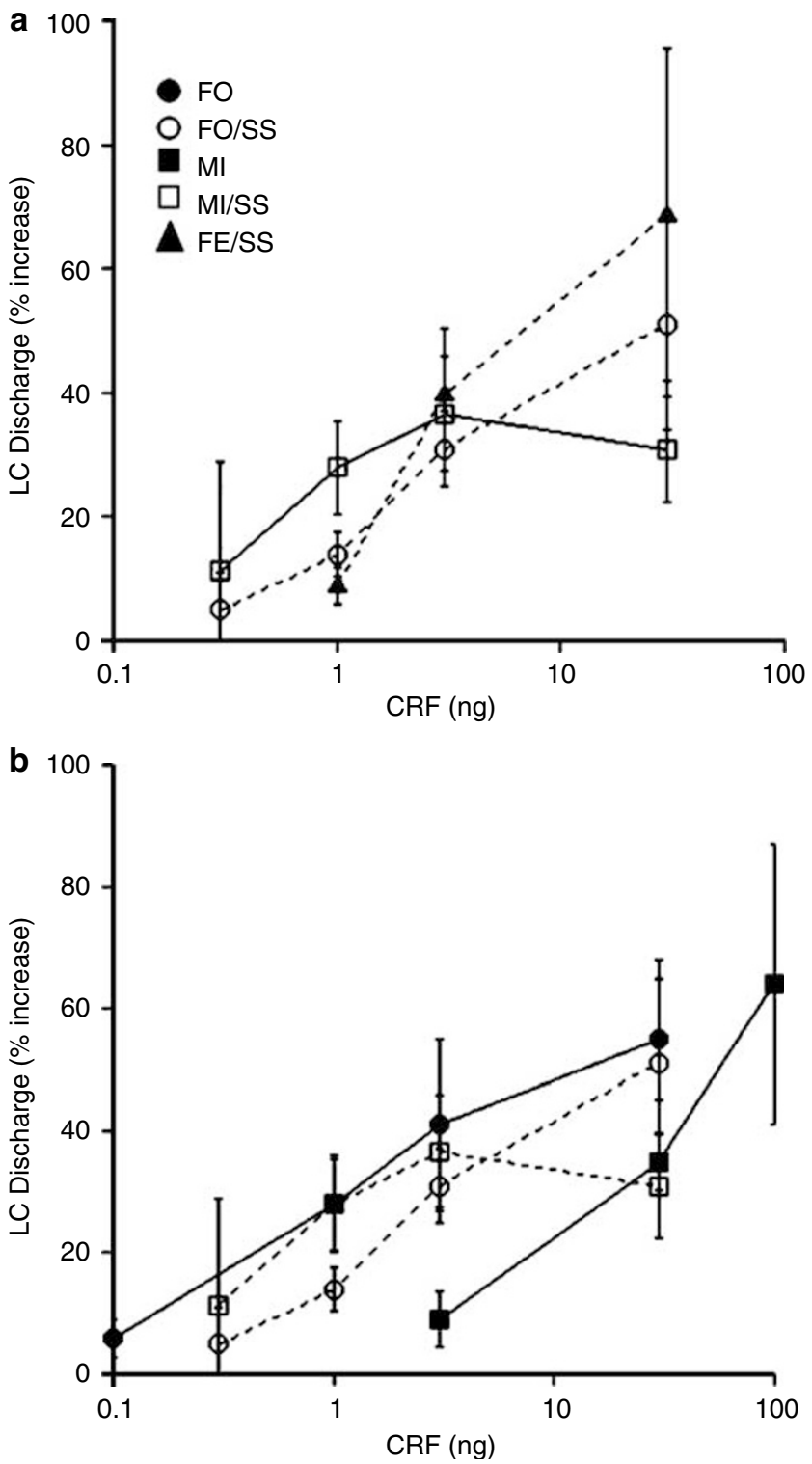

Figure 6 Prior swim stress differentially regulates $L C$ sensitivity to $C R F$ in male vs female rats. (a) CRF dose-response curves generated $24 \mathrm{~h}$ after swim stress in $\mathrm{MI}$ rats (MI/SS, $n=5-12$ cells), FO (FO/SS, $n=6-10$ cells), and FE (FE/SS, $n=4-12$ cells). Note the overlap between CRF doseresponse curves in all groups. (b) CRF dose-response curves in $\mathrm{FO}$ (circles) and $\mathrm{Ml}$ (squares) generated $24 \mathrm{~h}$ after swim stress (open symbols) are plotted with curves generated in same groups, with no prior stress history (filled symbols) (see Figure 2). Note that swim stress shifts the CRF doseresponse curve of male rats, but not female rats, to the left. The net effect is that low doses of CRF will have comparable effects in both groups.

range of the CRF dose-response curve compared to that generated in male rats with no prior stress history (Figure 6b). In contrast, LC neurons of FO were not sensitized to CRF. Rather, there was a trend for a slight shift to the right in the CRF dose-response curve generated in FO rats after swim stress, although this was not statistically significant $(\mathrm{F}(1,40)=1.1, p=0.3$, two-way ANOVA over 1$30 \mathrm{ng}$ doses) (Figure $6 \mathrm{~b}$ ). The net effect of prior stress was to render LC neurons of male and female rats equally sensitive to $\mathrm{CRF}$ and this translated to a comparable magnitude of LC 
activation elicited by an acute challenge (ie hypotension, Figure 5).

\section{DISCUSSION}

Previous studies documented an increased responsiveness of the HPA axis in female vs male rats (Kitay, 1961; Critchlow et al, 1963; Le Mevel et al, 1979; Seale et al, 2004). The present study is the first to demonstrate that, in parallel with the HPA axis, the brain NE system of female rats is more responsive to certain stressors. Moreover, this study provided evidence for substantial sex differences in CRF regulation of the LC-NE system that likely underlie sex differences in stress responsiveness of LC neurons. This included greater levels of CRF receptor protein in the LC, increased neuronal sensitivity to CRF and differential regulation of CRF-LC interactions by prior stress in female vs male rats. Unlike the sex differences in HPA axis responsivity, which have been attributed to circulating hormones (Burgess and Handa, 1992; Miller et al, 2004; Seale et al, 2004), sex differences in LC sensitivity were independent of adult hormonal status. Given the role of the LC-NE system in arousal and attention (Aston-Jones et al, 2000 ), the present results predict that the expression of these aspects of the stress response will be enhanced in females. This sexually dimorphic response could play a role in the increased prevalence of stress-related disorders, such as PTSD, functional pain syndromes, and depression in females (Chang and Heitkemper, 2002; Carter-Snell and Hegadoren, 2003; Kuehner, 2003). Finally, the finding that a prior history of stress sensitizes LC neurons of male (Curtis et al, 1995, 1999), but not female, rats to CRF implies sex differences in CRF receptor signaling in the LC and its longterm regulation.

\section{Sex Differences in LC Activation by Hypotensive Stress}

The LC-NE system is activated by diverse challenges, many of which also activate the HPA axis. While HPA activation is ultimately responsible for the diverse effects of corticosteroids, LC-NE activation is thought to facilitate increased arousal, alterations in attention, and to impact on memory during stress (Valentino and Van Bockstaele, 2005). Parallel activation of both systems during stress could be a means for coordinating endocrine and cognitive limbs of the stress response. Hypotensive challenge is one physiological stressor that activates both the HPA and LC-NE systems (Plotsky, 1985; Svensson, 1987), and engagement of the LCNE system during this challenge is necessary for the associated arousal response (Page et al, 1993). The finding that the same magnitude of hypotension elicited a more robust excitation of LC neurons of female compared to male rats demonstrates that this system shows similar sex differences in stress responsivity as the HPA axis. Although sex differences in morphological characteristics of the LC (Luque et al, 1992; Babstock et al, 1997; Pinos et al, 2001) and regulation of TH transcription (Thanky et al, 2002) have been documented, this is the first report of sex-related differences in LC neuronal activity in the rat.

A reliable component of the LC response to hypotensive stress is a poststress neuronal inhibition that is mediated by endogenous opioid release within the LC (Curtis et al, 2001). This has been hypothesized to facilitate return of LC activity to prestress baseline levels. The finding that the magnitude of poststress inhibition was comparable in all groups indicates that the attenuated excitation in males was not due to excessive opioid inhibition.

\section{Sex Differences in LC Activation by CRF}

Previous studies demonstrated that LC activation during hypotensive challenge is mediated by CRF release within the LC (Valentino et al, 1991; Curtis et al, 1994). Therefore, sex differences in this response could reflect differences in either CRF release (presynaptic effect) or in the postsynaptic response to CRF. The finding that the magnitude of the leftward shift of the CRF dose-response curve in females $v s$ males could completely account for the difference in response to hypotensive challenge indicated that the underlying basis for the sex differences lies with postsynaptic sensitivity to CRF.

Immunohistochemical detection of CRF-R using either Western blot or slide-mounted sections suggested sex differences in CRF-R levels. This was not well reflected in the comparison of CRF dose-response curves, which would be predicted to have different plateaus. However, due to solubility limitations of the peptide, complete doseresponse curves with true plateaus could not be generated, so that maximum effects could not be compared. Additionally, the interpretations of studies using these immunohistochemical approaches are limited by the sensitivity and specificity of the antiserum. In this regard, the antisera used in this study was directed against CRF-R1, but crossreacts with CRF-R2, so that sex differences in CRF-R levels could reflect differences in either receptor.

\section{Sex Differences in HPA vs LC Sensitivity to Stress}

Two noteworthy distinctions between sex differences in HPA and LC stress responses relate to (1) hormone dependence and (2) presynaptic $v s$ postsynaptic target. Although sex differences in HPA sensitivity appear to be hormone-dependent (Kitay, 1961; Critchlow et al, 1963; Le Mevel et al, 1979; Seale et al, 2004), sex differences in LC sensitivity to stress are independent of adult hormonal status. Sex differences in the LC response could arise from direct organizational actions of hormones on expression of CRF-R or components of the CRF-R signaling pathway in LC neurons during development. Alternatively, sex hormones may exert organizational effects on CRF expression in cells that project to the LC and thereby indirectly affect CRF-R expression in LC neurons. In this vein, estrogendependent organizational effects on CRF mRNA expression in paraventricular hypothalamic neurons have been reported (Patchev et al, 1995). These are one source of CRF that can impact on the LC (Reyes et al, 2005).

Several studies suggest that increased sensitivity of the HPA axis in females is related to induction of CRF transcription by estrogen receptor complex. The CRF promoter contains sites at which agonist-bound estrogen receptor complexes can affect transcription (Vamvakopoulos and Chrousos, 1993). More recently, estrogen receptor $\beta$-isoforms were found to be colocalized with CRF in a 
population of paraventricular hypothalamic neurons in rat and to regulate the CRF promoter in transfected cells (Miller et al, 2004). These findings are consistent with the idea that estrogen effects on CRF transcription (effects that are presynaptic to the pituitary) are related to the sexually dimorphic HPA response. The sexually dimorphic LC response described here differs from the HPA response in that it involves an increased postsynaptic response to CRF rather than increased CRF expression or release. Nonetheless, as some paraventricular hypothalamic CRF neurons project to the LC (Reyes et al, 2005), sex differences in CRF release in the LC that are not detected by the end points used in this study are also possible.

\section{Sex Differences in Stress-Induced Regulation of CRF-LC Interactions}

Prior exposure to stress (eg repeated footshock, repeated intraperitoneal saline injections, or a single exposure to swim stress) results in relatively long-term changes in LC sensitivity to CRF that are apparent as a change in the shape of the CRF dose-response curve from sigmoidal to biphasic (Curtis et al, 1995, 1999; Valentino and Van Bockstaele, 2005). Thus, LC neurons become sensitized to low doses of CRF and less sensitive to high doses. Although the cellular mechanisms underlying this type of dose-response curve shift have yet to be elucidated, pharmacological modeling suggested that this could result from binding to multiple sites or engagement of multiple signaling pathways (Curtis et al, 1999). This effect was reproduced in the present study only in male rats. The differential regulation of CRF postsynaptic responses by prior stress history is noteworthy and implies sex differences in CRF receptor structure and/ or intracellular signaling mechanisms that transduce stressrelated plasticity. As would be predicted, the selectively enhanced response of LC neurons to low doses of CRF translated to an enhanced response to hypotensive stress, such that LC neurons of male and female rats were now equally responsive. It is noteworthy that swim stress shifts the low-dose end of the male CRF dose-response curve to a position that matches the dose-response in females. It is possible that the basal state of the CRF-R in females is comparable to the stress-sensitized state in males.

Prior stress exposure had a unique effect on FE rats that was expressed as a decreased sensitivity of LC neurons to hypotensive challenge. This could not be attributed to a differential response to $\mathrm{CRF}$, implying a selective inhibitory effect on CRF release during the hypotensive challenge. As the CRF that activates LC neurons during hypotensive challenge derives from the central nucleus of the amygdala, it may be speculated that prior stress sets up a condition whereby estrogen can regulate CRF expression in amygdalar neurons that project to the LC (Curtis et al, 2002).

\section{Clinical Implications}

The higher incidence of depression and other stress-related disorders in females implies an increased sensitivity of stress-related systems or substrates. To date, the focus has been on elements of the HPA axis. Although there is substantial evidence for such a sexual differentiation in HPA sensitivity in rats (Kitay, 1961; Critchlow et al, 1963;
Le Mevel et al, 1979; Seale et al, 2004), this distinction is less clear in humans. Indeed, certain studies suggest that HPA drive is greater in males compared to females under certain conditions (Kirschbaum et al, 1999; Kudielka et al, 1998; Seeman et al, 2001; Traustadottir et al, 2003). The present findings demonstrate sex differences in another system that is engaged by stress, the brain norepinephrine system, which modulates cognitive aspects of the stress response. Increased stress sensitivity of this system could translate to elevated or inappropriate arousal, disruption of attention, and hypervigilance. Given that the LC-NE system has been implicated in depression, PTSD, and other stressrelated disorders, sex differences in the stress sensitivity of this system could contribute to the prevalence of these diseases in females. Importantly, because CRF analogs are being developed for use in psychiatric disorders, potential sex differences in CRF receptor function that may impact on the efficacy of these agents need to be taken into consideration.

\section{ACKNOWLEDGEMENTS}

This work was supported by PHS grants MH 63267 (ALC), MH40008, MH02006 (a Research Scientist Award to RJV), and a NARSAD Distinguished Investigator Award (RJV).

\section{REFERENCES}

Akaoka H, Saunier C-F, Chergui K, Charlety P, Buda M, Chouvet G (1992). Combining in vivo volume-controlled pressure microejection with extracellular unit recording. J Neurosci Meth 42: 119-128.

Aston-Jones G, Rajkowski J, Cohen J (2000). Locus coeruleus and regulation of behavioral flexibility and attention. Prog Brain Res 126: $165-182$.

Babstock D, Malsbury CW, Harley CW (1997). The dorsal locus coeruleus is larger in male than female Sprague-Dawley rats. Neurosci Lett 224: 157-160.

Berridge CW, Waterhouse BD (2003). The locus coeruleusnoradrenergic system: modulation of behavioral state and state-dependent cognitive processes. Brain Res Rev 42: 33-84.

Breslau N (2001). The epidemiology of posttraumatic stress disorder: what is the extent of the problem? J Clin Psychiatry 62(Suppl 17): 16-22.

Breslau N (2002). Gender differences in trauma and posttraumatic stress disorder. J Gend Specif Med 5: 34-40.

Burgess LH, Handa RJ (1992). Chronic estrogen-induced alterations in adrenocorticotropin and corticosterone secretion, and glucocorticoid receptor-mediated functions in female rats. Endocrinology 131: 1261-1269.

Carter-Snell C, Hegadoren K (2003). Stress disorders and gender: implications for theory and research. Can J Nurs Res 35: 34-55.

Chang L, Heitkemper MM (2002). Gender differences in irritable bowel syndrome. Gastroenterology 123: 1686-1701.

Chrousos GP, Gold PW (1992). The concepts of stress and stress system disorders. Overview of physical and behavioral homeostasis. JAMA 267: 1244-1252.

Critchlow V, Liebelt A, Barsela M, Mountcastle W, Lipscomb HS (1963). Sex differences in resting pituitary-adrenal function in the rat. Am J Physiol 205: 807-815.

Curtis AL, Bello NT, Connally KR, Valentino RJ (2002). Corticotropin-releasing factor neurons of the central nucleus of the amygdala mediate locus coeruleus activation by cardiovascular stress. J Neuroendocrinol 14: 667-682. 
Curtis AL, Bello NT, Valentino RJ (2001). Endogenous opioids in the locus coeruleus function to limit the noradrenergic response to stress. J Neurosci 21: RC152.

Curtis AL, Florin-Lechner SM, Pavcovich LA, Valentino RJ (1997). Activation of the locus coeruleus noradrenergic system by intracoerulear microinfusion of corticotropin-releasing factor: effects on discharge rate, cortical norepinephrine levels and cortical electroencephalographic activity. J Pharmacol Exp Ther 281: 163-172.

Curtis AL, Grigoradis D, Page ME, Rivier J, Valentino RJ (1994). Pharmacological comparison of two corticotropin-releasing factor antagonists: in vivo and in vitro studies. J Pharmacol Exp Ther 268: 359-365.

Curtis AL, Pavcovich LA, Valentino RJ (1995). Previous stress alters corticotropin-releasing factor neurotransmission in the locus coeruleus. Neuroscience 65: 541-550.

Curtis AL, Pavcovich LA, Valentino RJ (1999). Long term regulation of locus coeruleus sensitivity to corticotropinreleasing factor by swim stress. J Pharmacol Exp Ther 289: 1211-1219.

Earls F (1987). Sex differences in psychiatric disorders: origins and developmental influences. Psychiatr Dev 5: 1-23.

Frank E, Anderson B, Reynolds III CF, Ritenour A, Kupfer DJ (1994). Life events and the research diagnostic criteria endogenous subtype. A confirmation of the distinction using the Bedford College methods. Arch Gen Psychiatry 51: 519-524.

Frye CA, Bayon LE, Pursnani NK, Purdy RH (1998). The neurosteroids, progesterone and $3 \alpha, 5 \alpha$-THP, enhance sexual motivation, receptivity, and proceptivity in female rats. Brain Res 808: 72-83.

Gallucci WT, Baum A, Laue L, Rabin DS, Chrousos GP, Gold PW et al (1993). Sex differences in sensitivity of the hypothalamicpituitary-adrenal axis. Health Psychol 12: 420-425.

Gold PW, Chrousos GP (2002). Organization of the stress system and its dysregulation in melancholic and atypical depression: high vs low CRH/NE states. Mol Psychiatry 7: 254-275.

Gold PW, Goodwin FK, Chrousos GP (1988a). Clinical and biochemical manifestations of depression: relationship to the neurobiology of stress (Part 1). New Engl J Med 316: 348-353.

Gold PW, Goodwin FK, Chrousos GP (1988b). Clinical and biochemical manifestations of depression: relationship to the neurobiology of stress (Part 2). New Engl J Med 319: 413-420.

Jezova D, Jurankova E, Mosnarova A, Kriska M, Skultetyova I (1996). Neuroendocrine response during stress with relation to gender differences. Acta Neurobiol Exp (Wars) 56: 779-785.

Kendler KS, Kessler RC, Walters EE, MacLean C, Neale MC, Heath AC et al (1995). Stressful life events, genetic liability, and onset of an episode of major depression in women. Am J Psychiatry 152: 833-842.

Kirschbaum C, Kudielka B, Gaab J, Schommer N, Hellhammer D (1999). Impact of gender, menstrual cycle phase, and oral contraceptives on the activity of the hypothalamus-pituitaryadrenal axis. Psychosomatic Med 61: 154-162.

Kirschbaum C, Schommer N, Federenko I, Gaab J, Neumann O, Oellers M et al (1996). Short-term estradiol treatment enhances pituitary-adrenal axis and sympathetic responses to psychosocial stress in healthy young men. J Clin Endocrinol Metab 81: 3639-3643.

Kitay JI (1961). Sex differences in adrenal cortical secretion in the rat. Endocrinology 68: 818-824.

Kudielka BM, Hellhammer J, Hellhammer DH, Wolf OT, Pirke KM, Varadi E et al (1998). Sex differences in endocrine and psychological responses to psychosocial stress in healthy elderly subjects and the impact of a 2-week dehydroepiandrosterone treatment. J Clin Endocrinol Metab 83: 1756-1761.

Kuehner C (2003). Gender differences in unipolar depression: an update of epidemiological findings and possible explanations. Acta Psychiatr Scand 108: 163-174.
Le Mevel JC, Abitol S, Beraud G, Maniey J (1979). Temporal changes in plasma adrenocorticotropin concentration after repeated neurotropic stress in male and female rats. Endocrinology 105: 812-817.

Leonard BE (2001). Stress, norepinephrine and depression. J Psychiatry Neurosci 26: S11-S16.

Luque JM, de Blas MR, Segovia S, Guillamon A (1992). Sexual dimorphism of the dopamine-beta-hydroxylase-immunoreactive neurons in the rat locus coeruleus. Brain Res Dev Brain Res 67: 211-215.

Miller WJS, Suzuki S, Miller LK, Handa R, Uht RM (2004). Estrogen receptor (ER) $\beta$ isoforms rather than $\mathrm{ER} \alpha$ regulate corticotropin-releasing hormone promoter activity through an alternate pathway. J Neurosci 24: 10628-10635.

Nemeroff CB (1996). The corticotropin-releasing factor (CRF) hypothesis of depression: new findings and new directions. Mol Psychiatry 1: 336-342.

O'Connor TM, O'Halloran DJ, Shanahana F (2000). The stress response and the hypothalamic-pituitary-adrenal axis: from molecule to melancholia. Q J Med 93: 323-333.

Page ME, Berridge CW, Foote SL, Valentino RJ (1993). Corticotropin-releasing factor in the locus coeruleus mediates EEG activation associated with hypotensive stress. Neurosci Lett 164: $81-84$.

Patchev VK, Hayashi S, Orikasa C, Almeida OF (1995). Implications of estrogen-dependent brain organization for gender differences in hypothalamo-pituitary-adrenal regulation. FASEB J 9: 419-423.

Perrotti LI, Beck KD, Luine VN, Quinones V (2000). Progesterone and cocaine administration affect serotonin in the medial prefrontal cortex of ovariectomized rats. Neurosci Lett 291: $155-158$.

Pfaff DW, Schwaartz-Giblin S, McCarthy MM, Kow L-M (1994). Cellular and molecular mechanisms of female reproductive behaviors. In: Knobil E, Neill JD (eds). The Physiology of Reproduction. Raven Press: New York. pp 107-220.

Pinos H, Collado P, Rodriguez-Zafra M, Rodriguez C, Segovia S, Guillamon A (2001). The development of sex differences in the locus coeruleus of the rat. Brain Res Bull 56: 73-78.

Plotsky PM (1985). Hypophysiotropic regulation of adenohypophyseal adrenocorticotropin secretion. Fed Proc 344: 207-214.

Reyes BAS, Valentino RJ, Xu G, Van Bockstaele EJ (2005). Hypothalamic projections to locus coeruleus neurons in rat brain. Eur J Neurosci 22: 93-106.

Seale JV, Wood SA, Atkinson HC, Bate E, Lightman SL, Ingram CD et al (2004). Gonadectomy reverses the sexually diergic patterns of circadian and stress-induced hypothalamic-pituitary-adrenal axis activity in male and female rats. J Neuroendocrinology 16: $516-524$

Seeman TE, Singer B, Wilkinson CW, McEwen B (2001). Gender differences in age-related changes in HPA axis reactivity. Psychoneuroendocrinology 26: 225-240.

Stroud LR, Salovey P, Epel ES (2002). Sex differences in stress responses: social rejection versus achievement stress. Biol Psychiatry 52: 318-327.

Svensson TH (1987). Peripheral, autonomic regulation of locus coeruleus noradrenergic neurons in brain: putative implications for psychiatry and psychopharmacology. Psychopharmacology 92: 1-7.

Thanky NR, Son JH, Herbison AE (2002). Sex differences in the regulation of tyrosine hydroxylase gene transcription by estrogen in the locus coeruleus of TH9-LacZ transgenic mice. Brain Res Mol Brain Res 104: 220-226.

Traustadottir T, Bosch PR, Matt KS (2003). Gender differences in cardiovascular and hypothalamic-pituitary-adrenal axis responses to psychological stress in healthy older adult men and women. Stress 6: 133-140. 
Valentino RJ, Foote SL, Aston-Jones G (1983). Corticotropinreleasing factor activates noradrenergic neurons of the locus coeruleus. Brain Res 270: 363-367.

Valentino RJ, Page ME, Curtis AL (1991). Activation of noradrenergic locus coeruleus neurons by hemodynamic stress is due to local release of corticotropin-releasing factor. Brain Res 555: 25-34.

Valentino RJ, Van Bockstaele EJ (2005). Functional interactions between stress neuromediators and the locus coeruleus-norepinephrine system. In: Steckler T, Kalin NH, Reul JMHM (eds). Handbook of Stress and the Brain. Elsevier: Amsterdam. pp 465-486.

Vamvakopoulos NC, Chrousos GP (1993). Evidence of direct estrogenic regulation of human corticotropin-releasing hormone gene expression. Potential implications for the sexual dimorphism of the stress response and immune/inflammatory reaction. J Clin Invest 92: 1896-1902.

Vermetten E, Bremner JD (2002). Circuits and systems in stress. I. Preclinical studies. Depress Anxiety 15: 126-147.

Whitaker A, Davies M, Shaffer D, Johnson J, Abrams S, Walsh BT et al (1989). The struggle to be thin: a survey of anorexic and bulimic symptoms in a non-referred adolescent population. Psychol Med 19: 143-163. 